\title{
Are there Housing Bubbles in South Africa? Evidence from SPSM-Based Panel KSS Test with a Fourier Function
}

\author{
Tsangyao Chang and Wen-Chi Liu
}

Department of Finance

Feng Chia University, Taichung, Taiwan

Email: tychang@fcu.edu.tw

Email: vincent8@mail.dyu.edu.tw

\author{
Goodness C. Aye* and Rangan Gupta \\ Department of Economics \\ University of Pretoria, Pretoria, 0002, Pretoria, South Africa \\ Email: goodness.aye@gmail.com \\ Email: rangan.gupta@up.ac.za \\ *Corresponding author
}

\begin{abstract}
This study applies the panel KSS test with a Fourier function through the Sequential Panel Selection Method, proposed by Chortareas and Kapetanios (2009), to test whether housing bubbles exist in South Africa using the ratio of housing price to income in 9 provinces (i.e., Eastern Cape, Free State, Gauteng, KwaZulu-Natal, Limpopo, Mpumalanga, North West, Northern Cape, and Western Cape). Whereas other panel-based unit root tests are joint tests of a unit root for all members of a panel and are incapable of determining the mix of integrated of order zero $(I(0))$ series and integrated of order one $(I(1))$ series in a panel setting, the SPSM-based panel KSS with a Fourier function can clearly identify how many and which series in the panel are stationary processes by classifying a whole panel into a group of stationary and non-stationary series. The empirical results from several traditional panel-based, as well as standard pure time-series unit root tests, indicate that house price/income ratios for the nine provinces studied here are either stationary or non-stationary. However, results from the SPSM-based panel KSS with a Fourier function unequivocally indicate that house price/income ratios are stationary for the 9 provinces under study. These results indicate that housing bubbles do not exist in the 9 provinces of South Africa. Our test results have important economic and policy implications for South Africa.
\end{abstract}

Keywords: House Prices; Income; Panel KSS Unit Root Test; Fourier Function; 
Sequential Panel Selection Method; Non-Stationary

JEL classification: C23, R21

\section{Introduction}

Over the past decade, we have witnessed a global boom and sometimes burst in residential real estate prices, suggesting that a bubble may exist in housing markets throughout the world. This is not only in industrialized countries but also in some emerging markets. The objective of this paper is to test for the presence of bubbles in the South African housing market. The term "bubble" in economics refers to the increase in the price of an asset beyond the level required by economic fundamentals (Lansing, 2007). Bubbles are an observable economic phenomenon. Different series of theoretical setups for bubbles detection are presented in Thompson and Hickson (2006). However, bubbles manifest mainly in three different ways: First, naturally such as the bubble component on fiat money that appears due to confidence and convenience throughout agents transactions; second, due to informational monopolies, which gives big institutional traders privileged information that help them to manipulate the market thus creating price boom; and third through the coalition of governments plus running elites, who together prepare and generate economic events that involve a major part of the society (Jiménez, 2011).

One characteristic of a housing bubble is that the rapid increase of prices can result in an unsustainable level relative to household incomes. Several financial indicators have been developed to evaluate whether housing is fairly valued. The ratios of housing price to income (P-I ratio) and housing price to rent (P-R ratio) are two basic indicators often used. Under the circumstance of rising interest rate levels, the excessive value of P-I ratio will aggravate the affordability of households, since the monthly mortgage payment of a household will definitely go up with the increase of interest rate. High P-I ratio may imply that there exists considerable risk in the housing market, all else being equal. We show that if housing price and income or rent drift away from each other or are not cointegrated, this means housing bubble will be a sign of the housing market. In other words, if housing price and income (and/or) rent are not cointegrated, then P-I ratios or P-R ratios should behave like random walk, then housing bubble should burst in the near future.

This study attempts to investigate whether P-I ratios are characterized as stationary or non-stationary processes since it has several important economic and policy implications ${ }^{1}$. First, if P-I ratios are characterized as an integrated of order one $(I(1))$ process, then the shocks affecting these series will have permanent effects, thus

\footnotetext{
${ }^{1}$ We propose that if P-I ratios are non-stationary and this indicates that housing bubble might exist in the market, on the other hand, if P-I ratios are stationary this indicates that housing bubble won't exit in the market.
} 
shifting the P-I ratios equilibrium from one level to another. The random walk (non-stationary) property also implies that the volatility of house prices relative to income can grow without bound in the long run, which has consequences for housing operation and regulation. In other words, if there are permanent effects from shocks to the P-I ratios of a region, then the effects of a housing policy should last longer. On the other hand, if shocks to P-I ratios are temporary, then policies have short-lived effects. When P-I ratios temporarily deviate from the target, the government should not choose an unnecessary objective for its policy. Second, if P-I ratios are stationary, then it is possible to forecast the series' future movements based on past behavior. Contrastingly, if P-I ratios are non-stationary, then one is unable to forecast future activities of the house market. Third, stationary properties of P-I ratios are of great importance for economic modeling. Nelson and Plosser (1982) pointed out that whether data are modeled as a stationary trend or as a difference stationary process has important implications vis-à-vis modeling, testing, and forecasting. For policy-makers and finance professionals, Diebold and Kilian (2000) also propose that pre-testing for unit roots before applying forecasts yields superior forecasting performance, as opposed to the alternatives of always working with differenced series or always working with levels. Further, as is well-known, classical econometrics requires the use of stationary data to make valid inferences. However, if the variables in the system are cointegrated, then the first-differenced model needs to account for corrections to the long-run equilibrium to avoid model misspecification. All these require pretesting of the data to ensure the appropriate order of integration of the variables under study.

There are a number of studies on housing bubbles as can be seen in the literature review section. However, findings are often mixed, and this can be attributed to methodological flaws. We test for the presence of bubbles in the South African housing market by analyzing whether provincial-level P-I ratios in South Africa are stationary or non-stationary. We start by using standard time-series-based unit root tests. Stationarity of the P-I ratios would then imply an absence of housing bubbles. However, it is important to note that if the data is I(1) it indicates possibility but not necessarily the existence of bubbles, since it might not be explosive. Therefore, in addition to testing for unit root test using standard tests with the null of unit root against the alternative of stationarity, we implement direct tests of bubble detection, some of which tests for the null of random walk or I(1) against explosive behavior. In the latter case, rejection of the null would imply that bubble is present in the data. Finally, we also implement panel unit root tests which allow for cross-sectional dependence across the regions and also accounts for structural breaks in the time series. 
This paper is organized as follows. Section 2 presents the literature review while section 3 presents the data used in our study. Section 4 briefly describes the SPSM test proposed by Chortareas and Kapetanios (2009), and Section 5 presents our empirical results and some policy implications. Section 6 concludes the paper.

\section{Literature review}

This section presents a review of studies on housing bubbles. Himmelberg and Mayer (2005) use annual imputed-to-actual-rental cost of owning a house, imputed-to-actual-income and the historical trends to study the existence or otherwise of bubbles. They could not find strong evidence of bubbles at both national and metropolitan levels in the US. Smith and Smith (2006) also could not find evidence for bubbles in the US housing market and Cameron et al. (2006) using a more traditional economic fundamentals-based model find similar result for the UK. Shen et al. (2005) investigates the Beijing and Shanghai housing markets using a Granger causality test and generalized impulse response analysis and based on economic fundamentals (disposable income of urban households, GDP and the stock price indices) find housing bubble in 2003 in only the Shanghai housing market. Mikhed and Zemčík (2009) use Pesaran (2007) cross-sectionally augmented Dickey-Fuller regression to test for housing bubbles in the US metropolitan areas and find bubbles in essentially all areas. Combining overlapping 10-year periods, price-rent ratios, and the panel data tests, they construct a bubble indicator, which is high for the late 1980s, early 1990s and since the late 1990s for the aggregate house price data. While Mikhed and Zemčík (2009) account for cross-sectional dependence across the panels, they did not account for structural breaks which will likely invalidate the results. Pavlidis, et al. (2009) using the supADF (or supDF for short) unit root test provide evidence of bubble behavior in some aggregate and regional US real house price indices especially in the last few years. Phillips and Yu (2011) based on a modified version of the supDF test investigate for bubbles in the monthly US house price-rent ratio and find evidence of bubbles in the housing market prior to the subprime crisis and collapsed with the subprime crisis. Homm and Breitung (2012) tested for bubbles using sequential Chow-type Dickey-Fuller (supDFC) test and the supDF test of Phillips et al. (2011) and find that prior to the subprime crisis, the US, UK, and Spanish monthly real house price indices exhibited explosive behaviour. Ren et al. (2012) based on data from 35 cities in China and using the theory of rational expectation bubbles proposed by Blanchard and Watson (1983) find no evidence to support the existence of bubbles in the Chinese housing market. Chen et al. (2013) investigates whether a bubble existed in the Beijing housing market from 1998 to 2010 using a VECM-based model and finds that the Beijing house price index was 
significantly larger than the equilibrium value, based on the relative economic fundamental variables (income, inflation, interest rate and construction cost) during 2004 to 2007.

As far as South Africa, our study area is concerned, there is only one study (Das et al., 2011) on housing price bubbles. Das et al. (2011) tested for bubbles in the real house prices in the five major segments of the South African housing market ${ }^{2}$ using the supDF test. Their results indicated existence of house price bubbles in the entire-middle, large-middle, medium-middle and small-middle segments (starting towards the end of 2002) but not in the affordable and luxury segments. The current study deviates from Das et al. (2011) in two ways. Firstly, instead of using real house prices with no fundamentals as in Das et al. (2011), we use the price-income ratio which incorporates fundamentals for testing bubbles in the housing market. ${ }^{3}$ This is important, since, by definition, housing bubbles exists, when the price is no longer determined by the fundamentals, and income is one major variable that determines house prices. In other words, house prices can be explosive, but so can be income, leading to the ratio being stationary. Hence, merely looking at house prices could result in misleading conclusions regarding the existence of bubbles. Also, as indicated by Breitung and Homm (2012), the supDF test, on which Das et al., (2011) base their conclusions on, have limitations in the sense that it does not use all available information. Secondly, we focus on the regional (provincial) housing markets since information on bubbles at the national level, contains no information regarding the possible source of the bubbles. This is important, since housing markets are more regional in nature than national (Simo-Kengne et al., 2012; 2013), and hence, there is no guarantee that existence of bubbles in the national market will automatically translate into existence of bubbles at the regional level. Also, we contribute to both the South African study and international studies by taking a panel approach that accounts for both cross-sectional dependence and structural breaks in testing for bubbles in the South Africa's regional housing market. The only known study close to ours is Clark and Coggin (2011) who used the LM (Lagrange Multiplier) unit root t-test of Lee and Strazicich (2003, 2004), which allows a single endogenous (unknown) break to test for bubbles in the US national and regional panel house prices data and find that overall, the house prices have unit roots. While this study accounts for both cross-sectional dependence and structural breaks, it imposes a priori a single break on the time series. There is no specific guide to determine actual nature and number of breaks to use in testing for unit roots. Using an incorrect specification

\footnotetext{
${ }^{2}$ See Section 2 relating to the data for further details on the structure of the South African housing market.

3 The price-to-income ratio provides a measure of local housing costs relative to the local ability to pay (Himmelberg and Mayer, 2005).
} 
or number of breaks is as bad as ignoring structural breaks (Maddala and Kim, 1998). Therefore, our study in contrast to Clark and Coggin (2011) allows for multiple unknown breaks in the panel data testing procedure.

\section{Data}

Our empirical analysis covers a sample of 9 provinces of South Africa: Eastern Cape, Free State, Gauteng, KwaZulu-Natal, Limpopo, Mpumalanga, North West, Northern Cape, and Western Cape, and their corresponding annual housing price and income over the period 1995-2011. A ratio of housing prices to income (P-I ratios) is calculated for each province, with the house prices obtained from Allied Bank of South Africa (ABSA) ${ }^{4}$, while, the nominal GDP comes from Statistics South Africa.

\section{Methodology - Sequential Panel Selection Method and Panel KSS Unit Root Test with a Fourier Function}

In the same vein as Balcilar et al. (2011), we highlight the existence of nonlinear behaviour in South African house prices in our unit root testing procedure. It must be realized that the behaviour of the housing market is not the same across phases of expansion and contraction that characterize the real estate sector (Kim and Bhattacharya, 2009). Seslen (2004) argued that households exhibit forward looking behaviour and have a higher probability of trading up during the upswing when equity constraints are less binding. However, the same is not true during the downswing of the housing market cycle, since when house prices are on the decline, households are less likely to trade; thus there is some downward rigidity of house prices. The aversion to loss during the downswing is more than likely to reduce the mobility of households as far as trading is concerned. Further, as pointed out by Muellbauer and

\footnotetext{
4 Note that ABSA is one of the leading private banks in South Africa and represents one of the two well known sources of residential property market data in the country. ABSA categorizes housing into three price segments, namely luxury (ZAR 3.5 million - ZAR 12.8 million), middle (ZAR 480,000 ZAR 3.5 million) and affordable (below ZAR 480,000 and area between 40 square metres - 79 square metres). The middle segment is further categorized into three more segments based on sizes, namely large-middle (221 square metres - 400 square metres), medium-middle (141 square metres - 220 square metres) and small-middle ( 80 square meters - 140 square meters). Additionally, house prices are also available for the entire middle-segment. However, no house price data is available at the provincial level for the luxury and affordable sections. Hence, for provincial level house price data, we use the house prices corresponding to the entire middle-segment, as this is the best possible representation of the average house price prevailing in each of the regions. Also, the data on income for the provinces are not available based on the categories of housing.
} 
Murphy (1997), the presence of lumpy transaction costs in the housing market can also cause nonlinearity. Given these issues, it is important and makes sense to incorporate nonlinearity in the data generating process of housing prices to income ratio. A number of studies have provided empirical evidence on the nonlinear adjustment of financial time series data. However, the finding of nonlinear adjustment does not necessarily imply nonlinear mean reversion. As such, stationarity tests based on a nonlinear framework must be applied. Ucar and Omay (2009) proposed a nonlinear panel unit root test by combining the nonlinear framework in Kapetanios et al. (2003, KSS) with the panel unit root testing procedure of Im et al. (2003), which has been proved to be useful in testing the mean reversion of financial time series data. Perron (1989) argued that if there is a structural break, the power to reject a unit root decreases when the stationary alternative is true and the structural break is ignored. Meanwhile, ignoring structural changes present in the data generating process biases the analysis toward accepting the null hypothesis of a unit root. Therefore, the Sequential Panel Selection Method (SPSM) proposed by Chortareas and Kapetanios (2009), mixed with the Panel KSS unit root test with a Fourier function are used to test housing bubbles in 9 provinces of South Africa country in our study.

The nonlinear panel unit root test is similar to Kapetanios et al.'s (2003) test for an individual time-series variable in spirit. Following Ucar and Omay (2009) we begin with:

$\Delta(\text { hp / income })_{i, t}=\xi_{i}+\delta_{i}(\text { hp / income })_{i, t-1}^{3}+\sum_{j=1}^{k} \theta_{i, j} \Delta(\text { hp / income })_{i, t-j}+v_{i, t}$

where the null and alternative hypothesis are given by:

$H_{0}: \delta_{i}=0$, for all i, (linear nonstationarity)

$H_{1}: \delta_{i}=0$, for some $\mathrm{i}$, (nonlinear stationarity)

We then incorporate a Fourier function into (1):

$$
\begin{aligned}
& \Delta(\text { hp } / \text { income })_{i, t}=\xi_{i}+\delta_{i}(\text { hp } / \text { income })_{i, t-1}^{3}+\sum_{j=1}^{k 1} \theta_{i, j} \Delta(\text { hp / income })_{i, t-j}+ \\
& a_{i, 1} \sin \left(\frac{2 \pi k t}{T}\right)+b_{i, 1} \cos \left(\frac{2 \pi k t}{T}\right)+\varepsilon_{i, t}
\end{aligned}
$$

where $t=1,2, \ldots, T$. The rational for selecting $[\sin (2 \pi k t / T), \cos (2 \pi k t / T)]$ is based on the fact that a Fourier expression is capable of approximating absolutely integrable functions to any desired degree of accuracy. In (2) k represents the frequency selected for the approximation, and $\left[a_{i}, b_{j}\right]^{\prime}$ measures the amplitude and displacement of the frequency component. It also follows that at least one frequency component must be present if there is a structural break. ${ }^{5}$ In applying the Chortareas

\footnotetext{
5 Enders and Lee (2012) suggest that the frequencies in (2) should be obtained via the minimization of
} 
and Kapetanios (2009) SPSM procedure we take following steps:

(1) Equation (2) is first estimated for the entire panel. If the unit-root null is not rejected, we accept that series in the panel are nonstationary and move to step 2.

(2) Remove the series with the minimum KSS statistic since it is identified as being stationary.

(3) Return to step 1 for the remaining series, or stop the procedure if all the series are removed from the panel.

Final result is a separation of the whole panel into a set of mean-reverting series and a set of non-stationary series.

\section{Empirical Results}

\subsection{Unit Root Tests}

Several univariate time series unit root tests are first employed to examine the null of a unit root for P-I ratios for the 9 provinces of South Africa. Then, both first-generation and second-generation panel unit root tests are employed. Table 1 reports the results of two univariate unit root tests - the Augmented Dickey and Fuller (1981, ADF) and the Phillips and Perron (1988, PP) tests. The results show that the housing P-I ratios of the 9 provinces in South Africa contain unit roots. This result is consistent with the existing literature and may be due to the low power of these two univariate unit root tests when the P-I ratios are highly persistent. Another reason for finding (possibly spurious) unit roots could be, as have recently been argued, that house prices are likely to be nonlinear due to the existence of transaction costs and hence the power of these two tests might be poor in such situations ( $\mathrm{Wu}$ and Lee, 2009). Furthermore, we know that univariate unit root tests might have low power when they are applied to a finite sample, which in our case comprises of only seventeen time-series observations. In this situation, panel-based unit tests are found to be of great help, provided that they allow for an increase in the power of the analysis by allowing the cross-sectional and temporal dimensions to be combined.

However, before turning to the panel unit root tests, we also implemented three alternative tests on detecting bubbles, two of which allow for regimes to switch between the unit root and explosive episodes. The results are presented in Table 2. First is the modified Busetti and Taylor (2004) statistic (supBT) for testing the hypothesis that a time series is stationary against the alternative that it switches from a stationary to an $I(1)$ process at an unknown breakpoint. The results in Table 2 indicate that the null of stationarity cannot be rejected, thus favouring the non-existence of 
bubbles. Second is the Phillips, et al. (2011) sequential Dickey-Fuller tests (supDF) with the null hypothesis of a random walk against the alternative of explosive process. The identification of explosive characteristics in the data is equivalent to the detection of a bubble (Diba and Grossman, 1978, 1988; Phillips, et al., 2011). The test rejects the null of a random walk in favour of an explosive process for all provinces, meaning that the regional housing market exhibits bubbles. The third is the Homm and Breitung (2012) sequential Chow-type Dickey-Fuller (supDFC) bubble test for a random walk hypothesis against the alternative of a change from random walk i.e. $I(1)$ to explosive in the interval. If the time series have changed from I(1) to explosive, this would suggest the presence of bubbles (Homm and Breitung, 2012). This test rejects the null of unit root in favour of bubbles or explosive behaviour for only two out of the nine provinces. Clearly the evidence is mixed in terms of whether the series is $\mathrm{I}(0)$ or I(1), and also in determining the existence of bubbles. However, as with the standard time-series based unit root tests, these tests too might suffer from small-sample bias. Further, although, two of these tests allow for regimes that switch between the unit root and explosive episodes, none of the three tests takes into account cross sectional dependence amongst the regional markets. Therefore, the results cannot be fully relied on, and hence, we turn to panel-based tests.

\subsection{First and Second Generation Panel Unit Root Tests}

Tables 3 and 4 report the results for the first-generation and second-generation panel-based unit root tests for P-I ratios of the 9 provinces, respectively. By looking at Table 3 shows that the first-generation panel-based unit root test of the LLC (Levin et al., 2002) yield similar results indicating that housing P-I ratios in all 9 provinces of South Africa are non-stationary. However, the results from both IPS (Im et al., 2003) test and Maddala and Wu (1999) indicate that housing P-I ratios are stationary. Table 4 shows that four second-generation panel-based unit root tests yield different results. Based on Table 4, we find that both Bai and $\mathrm{Ng}$ (2004) and Moon and Perron (2004) test results indicate that P-I ratios for all 9 provinces are stationary. However, results from both Choi (2002) and Pesaran (2007) tests indicate that P-I ratios for all 9 provinces are non-stationary.

As stated earlier, both the first and second-generation panel-based unit root tests are joint tests of a unit root for all members of a panel, and hence, are incapable of determining the mix of $I(0)$ and $I(1)$ series in a panel setting. To identify how many areas, and which areas in the panel support the non-stationary process, we proceed to the SPSM procedure combined with the Panel KSS unit root test.

\subsection{Panel KSS Test using Sequential Panel Selection Method (SPSM)}


As a benchmark, we first report the results of Panel KSS unit root test without a Fourier function on housing prices/income ratios for 9 provinces. Table 5 first reports the results from the Panel KSS unit root test without a Fourier function on housing prices/income ratios for 9 provinces. Table 5 first reports a sequence of the Panel KSS statistics with their bootstrap $p$-values ${ }^{6}$ on a reducing panel, the individual minimum KSS statistic, and the stationary series identified by this procedure for each value. If we look at the Table 5, we find that the null hypothesis of unit root in P-I ratios are rejected, when the Panel KSS unit root test is first applied to the whole panel, producing a value of -2.2745 with a very small $p$-value of 0.0692 . After implementing the SPSM procedure, we find Limpopo is stationary with the minimum KSS value of -2.8308 among the panel. Limpopo is then removed from the panel and the Panel KSS unit root test is implemented again to the remaining set of series. After that, we find that the Panel KSS unit root test still rejected the unit root null with a value of -2.2452 (p-value of 0.0704), and Northern Cape is found to be stationary with the minimum KSS value of -2.7613 in the panel this time. Northern Cape is then removed from the panel and the Panel KSS unit root test is implemented again for the remaining set of series. The procedure is continued until the Panel KSS unit root test fails to reject the null hypothesis of unit root at the $10 \%$ significance level, and finally we find that this procedure stops at the 3 sequence, when the P-I ratios for two provinces have been removed from the panel. Thus, the SPSM procedure using the Panel KSS unit root test without a Fourier function provides weak evidence favoring the mean-reverting in P-I ratios for only 2 provinces (i.e., Limpopo and Northern Cape) of South Africa.

As we indicated earlier Perron (1989) argued that if there is a structural break, the power to reject a unit root decreases when the stationary alternative is true and the structural break is ignored. Meanwhile, structural changes present in the data generating process, but which have been neglected, biases the analysis toward accepting the null hypothesis of a unit root. Therefore, we shift to the Panel KSS unit root test with a Fourier function. First, a grid-search is performed to find the best frequency, as there is no a priori knowledge concerning the shape of the breaks in the data. We estimate equation (2) for each integer $k=1, \ldots, 3$ following the recommendations of Enders and Lee (2012) that a single frequency can capture a wide variety of breaks. The residual sum of squares (RSSs) indicates that a frequency $(k=3)$ works best for all of the series (see the fourth column at the Table 5).

Table 6 reports the results from the Panel KSS unit root test with a Fourier function on P-I ratios for 9 provinces, where we also give a sequence of the Panel KSS statistics with their bootstrap $p$-values on a reducing panel, the individual minimum KSS statistic, and the stationary series identified by this procedure for each

\footnotetext{
6 The asymptotic $p$-values are computed by means of Bootstrap simulations using 5,000 replications.
} 
value. If we look at the Table 5, we find that the null hypothesis of unit root in P-I ratio is rejected, when the Panel KSS unit root test is first applied to the whole panel, producing a value of -4.7591 with a very small $p$-value of 0.0168 . After implementing the SPSM procedure, we find Northern Cape is stationary with the minimum KSS value of -2.8119 among the panel. Northern Cape is then removed from the panel and the Panel KSS unit root test is implemented again to the remaining set of series. After that, we find that the Panel KSS unit root test still rejected the unit root null with a value of -4.5962 (p-value of 0.0280), and Limpopo is found to be stationary with the minimum KSS value of -2.8308 in the panel this time. Limpopo is then removed from the panel and the Panel KSS unit root test is implemented again for the remaining set of series. The procedure is continued until the Panel KSS unit root test fails to reject the null hypothesis of unit root at the $10 \%$ significance level, and finally we find that this procedure stops at the 9 sequence, when the housing prices/income ratios for all the 9 provinces have been removed from the panel. Thus, the SPSM procedure using the Panel KSS unit root test without a Fourier function provides evidence favoring the mean-reverting in housing P-I ratios for 9 provinces of South Africa. These results indicate that housing bubbles do not exist in 9 provinces of South Africa. If we look at both Tables 5 and 6 , the results from these two tables point to the importance of proper modeling of structural breaks and nonlinearities in housing P-I ratios for South Africa

Figure 1 displays the time paths of housing P-I ratios for the 9 provinces, respectively. We can clearly observe structural shifts in the trend of the data after the 2000s. Accordingly, it appears sensible to allow for structural breaks in testing for a unit root (and/or stationarity). The estimated time paths of the time-varying intercepts are also shown in Figure 1. As we know that the actual nature of break(s) is generally unknown, and there is no specific guide as to where and how many breaks should be used in testing for a unit root or stationarity, using an incorrect specification for the form and number of breaks can be as problematic as ignoring the breaks altogether. A further examination of the figures indicates that all the Fourier approximations seem reasonable and support the notion of long swings in house prices/income ratios of the 9 provinces, respectively.

\section{Conclusions}

This study applies the panel KSS test with a Fourier function through the Sequential Panel Selection Method, proposed by Chortareas and Kapetanios (2009), to test whether housing bubbles exist in South Africa using the ratio of housing price to income (P-I ratios) in 9 provinces (i.e., Eastern Cape, Free State, Gauteng, KwaZulu-Natal, Limpopo, Mpumalanga, North West, Northern Cape, and Western 
Cape). Whereas other panel-based unit root tests are joint tests of a unit root for all members of a panel and are incapable of determining the mix of integrated of order zero $(I(0))$ series and integrated of order one $(I(I))$ series in a panel setting, the SPSM-based panel KSS test with a Fourier function can clearly identify how many and which series in the panel are stationary processes by classifying a whole panel into a group of stationary and non-stationary series. Moreover, the approach handles both nonlinearities, structural breaks and cross sectional dependence across provinces. The empirical results from several panel-based, as well as standard pure time-series, unit root tests, indicate that P-I ratios for the nine provinces studied here are either stationary or non-stationary. However, results from the SPSM-based panel KSS test with a Fourier function unequivocally indicate that P-I ratios are stationary for the 9 provinces under study ${ }^{7}$ Our test results have important economic and policy implications for South Africa. The non-existence of bubbles which indicates stationarity of the P-I ratios implies that shocks to the regional estate markets will only be temporary and hence exhibits temporary impact on real economic variables. Therefore, accurate predictions of these series are possible and will be of benefit to businesses, investors, consumers and policy makers as they understand the dynamics of the housing market. This is because accurate forecasting has implications for cash flow, liquidity, future revenues and hence consumption. These in turn influence the entire real economy. The stability of the series and cross sectional dependence also indicates good prospects for real estate development in the South African provinces. Overall, we acknowledge the fact that definition of a bubble is often problematic and hence the findings in this study may depend on the particular definition of bubble used.

\section{References}

Bai, J. and Ng. S. 2004. A panic attack on unit roots and cointegration. Econometrica, 72:1127-1177.

Balcilar, M., Gupta, R. and. Shah, Z. 2011. An in-sample and out-of-sample empirical investigation of the nonlinearity in house prices of South Africa. Economic Modelling, 28(3):891-899.

Blanchard, O. and Watson, M. 1983. Bubbles, rational expectations and financial markets. NBER Working Papers 1983.

Busetti, F. and Taylor, A. M. R. 2004. Tests of stationarity against a change in persistence. Journal of Econometrics, 123: 33-66.

\footnotetext{
${ }^{7}$ Interestingly, when we used the time series version of the KSS test with a Fourier function to test for stationarity of the price-income ratio at the national level over the period of 1995-2011, we rejected the null of unit root, implying the lack of bubbles at the national level as well. These results are available upon request from the authors.
} 
Cameron, G., Muellbauer, J. and Murphy, A. 2006. Was there a British house price bubble? Discussion Paper no. 5619. Centre for Economic Policy Research, London.

Chen, R.D., Gan, C., Hu, B. and Cohen, D.A. 2013. An empirical analysis of house price bubble: a case study of Beijing housing market. Research in Applied Economics, 5(1): 77-97.

Choi, I. 2002. Combination unit root tests for cross-sectionally correlated panels. in The Econometric Theory and Practice: Frontiers of Analysis and Applied Research, Essays in Honor of Peter C. B. Phillips. D. Corbae, S.N. Durlauf and B.E. Hansen (eds.). Cambridge University Press, Cambridge, UK, 311-333.

Chortareas, G. and Kapetanios, G. 2009. Getting PPP right: identifying mean-reverting real exchange rates in panels. Journal of Banking and Finance, 33:390-404. Clark, S.P. and Coggin, D.T. 2011. Was there a U.S. house price bubble? An econometric analysis using national and regional panel data. The Quarterly Review of Economics and Finance, 51: 189-200.

Das, S., Gupta, R. and Kanda, P.T. 2011. Bubbles in South African house prices and their impact on consumption. Journal of Real Estate Literature, 19(1): 71-91.

Diba, B. and Grossman, H. 1987. On the inception of rational bubbles. Quarterly Journal of Economics, 87: 697-700.

Diba, B. and Grossman, H. 1988. Explosive rational bubbles in stock prices. American Economic Review, 78: 520-30.

Dickey, D.A. and Fuller, W.A. 1981. Likelihood ratio statistics for autoregressive time series with a unit root. Econometrica, 49:1057-1072.

Diebold, F.X. and Kilian, L. 2000. Unit-root tests are useful for selecting forecasting models. Journal of Business and Economic Statistics, 18, 265-273.

Enders, W. and Lee, J. 2012. A unit root test using a fourier series to approximate smooth breaks. Oxford Bulletin of Economics and Statistics, 74(4):574-599.

Himmelberg, C. and Mayer, C. 2005. Assessing high house prices: bubbles, fundamentals and misperceptions. Journal of Economic Perspectives, 19(4): 67-92.

Homm, U. and Breitung, J. 2012. Testing for speculative bubbles in stock markets: A comparison of alternative methods. Journal of Financial Econometrics, 10(1): 198-231.

Im, K. S., Pesaran, M.H. and Shin, Y. 2003. Testing for unit roots in heterogeneous panels. Journal of Econometrics, 115:53-74.

Jiménez, Á.J. 2011. Understanding economic bubbles. Programa Universitat-Empresa.http://www.eco.uab.es/ue/trabajos\%20premi/tfc\%2061\%20Ji m\%C3\%A9nez\%201.pdf. 
Kapetanios, G., Shin, Y., and Snell, A. 2003. Testing for cointegration in nonlinear smooth transition error correction models. Econometric Theory, 22:279-303.

Kim, S. and Bhattacharya, R. 2009. Regional housing prices in the USA: An empirical investigation of nonlinearity. Journal of Real Estate Finance and Economics, 38(4): 443-460.

Lansing, K.J. 2007. Asset Price Bubbles. FRBSF Economic Letter, 32, $25-9$.

Lee, J., and Strazicich, M. C. 2003. Minimum Lagrange multiplier unit root test with two structural breaks. Review of Economics and Statistics, 85, 1082-1089.

Lee, J. and Strazicich, M. C. 2004. Minimum LM unit root test with one structural break. Working paper. Department of Economics, Appalachian State University. http://econ.appstate.edu/RePEc/pdf/wp0417.pdf.

Levin, A., Lin, C.F. and Chia-Shang Chu. 2002. Unit root in panel data: asymptotic and finite-sample properties. Journal of Econometrics, 108:1-24.

Maddala, G. and Kim, I.-M. 1998. Unit roots, cointegration and structural change, Cambridge University Press, UK.

Maddala, G.S. and Wu, S. 1999. A comparative study of unit root tests with panel data and a new simple test. Oxford Bulletin of Economics and Statistics, 61: 631-652.

Mikhed, V. and Zemčík, P. 2009. Testing for bubbles in housing markets: a panel data approach. J Real Estate Finan Econ,38:366-386.

Moon, H. R. and Perron, B. 2004. Testing for a unit root in panels with dynamic factors. Journal of Econometrics, 122:81-126.

Muellbauer, J. and Murphy, A. 1997. Booms and busts in the UK housing market. The Economic Journal, 445:1701-1727.

Nelson, C. R., and Plosser, C. I. 1982. Trends and random walks in macroeconomic time series: Some evidence and implications. Journal of Monetary Economics, 10:139-162.

Pavlidis, E., Paya, I. Peel, D. and Spiru, A. 2009. Bubbles in house prices and their impact on consumption: evidence for the US. Lancaster University Management School working paper, no. 025.

Perron, P. 1989. The great crash, the oil price shock and the unit root hypothesis, Econometrica, 57: 1361-401.

Pesaran, M.H. 2004. General diagnostic tests for cross section dependence in panels. IZA Discussion Papers 1240, Institute for the Study of Labor (IZA).

Pesaran, M.H. 2007. A simple unit root test in the presence of cross-section dependence. Journal of Applied Econometrics, 22:265-312.

Phillips, P. C. B., and Perron, P. 1988. Testing for a unit root in time series regression. Biometrika, 75:335-346. 
Phillips, P.C.B., and Yu, J. 2011, Dating the timeline of financial bubbles during the subprime crisis. Quantitative Economics, 2, 455-491.

Phillips, P. C. B., Y. Wu, and J. Yu. 2011. Explosive behavior in the 1990s Nasdaq: When did exuberance escalate asset values? International Economic Review, 52(1): 201-226.

Ren, Y., Xiong, C. and Yuan, Y. 2012. House price bubbles in China. China Economic Review, 23: 786-800.

Seslen, N. 2004. Housing price dynamics and household mobility decisions. Seminar Paper,USC Lusk/FBE Real Estate Seminar, September.

Shen, Y., Hui, E. C., and Liu, H. 2005. Housing price bubble in Beijing and Shanghai. Management Decision, 43(4): 611-627.

Simo-Kengne, B.D., Bittencourt, M. and Gupta, R. 2012. House prices and economicgrowth in South Africa: Evidence from provincial-level data. Journal of Real Estate Literature, 20(1):97-117.

Simo-Kengne, B.D., Bittencourt, M. and Gupta, R. 2013. The impact of house prices on consumption in South Africa: Evidence from provincial-level panel VARs. Housing Studies, 28(8):1133-1154.

Smith, M. H. and Smith, G. 2006. Bubble, bubble, where's the housing bubble? Brookings Papers on Economic Activity, 1-50.

Thompson, E. and Hickson, C. 2006. Predicting bubbles. Global Business and Economics Review, 8(3/4), 217-246.

Ucar, N. and Omay, T. 2009. Testing for unit root in nonlinear heterogeneous panels, Economics Letters, 104:5-8.

Wu, J.L. and Lee, H.Y. 2009. A revisit to the non-linear mean reversion of real exchange rates: evidence from a series-specific non-linear panel unit-root test, Journal of Macroeconomics, 31:591-601. 
Table 1. Univariate Unit Root Tests

\begin{tabular}{lllll}
\hline Province & \multicolumn{3}{c}{ ADF } & PP \\
\cline { 2 - 5 } & Intercept & Intercept \& trend & Intercept & Intercept \& trend \\
\cline { 2 - 5 } Eastern Cape & -1.898 & -2.627 & -1.203 & -1.388 \\
Free State & -0.485 & -3.264 & -0.556 & -1.938 \\
Gauteng & -1.555 & -2.828 & -1.080 & -1.105 \\
KwaZulu-Natal & -1.953 & -2.289 & -1.173 & -1.478 \\
Limpopo & -1.849 & -1.782 & -1.314 & -1.101 \\
Mpumalanga & -1.732 & -2.614 & -1.027 & -1.572 \\
North West & -1.346 & -3.150 & -0.780 & -1.761 \\
Northern Cape & -1.526 & -1.924 & -0.857 & -1.590 \\
Western Cape & -0.466 & -2.496 & -0.551 & -1.756 \\
\hline
\end{tabular}

Note: For the ADF test with intercept, the critical values are $-3.959,-3.081$ and -2.681 respectively, for $1 \%, 5 \%$ and $10 \%$ level of significance while the corresponding values for intercept and trend are $-4.886,-3.829$ and -3.363 . For the PP test with intercept, the critical values are $-3.920,-3.066$ and -2.673 respectively, for $1 \%, 5 \%$ and $10 \%$ level of significance while the corresponding values for intercept and trend are $-4.668,-3.733$, and -3.310 .

Table 2: Univariate Bubbles Test

\begin{tabular}{llll}
\hline Province & supBT & supDF & supDFC \\
\hline Eastern Cape & 0.995 & $2.337^{*}$ & 0.450 \\
Free State & 1.263 & $2.988^{* *}$ & 1.551 \\
Gauteng & 0.947 & $4.796^{* * *}$ & 1.162 \\
KwaZulu-Natal & 0.728 & $2.745^{* *}$ & 0.575 \\
Limpopo & 0.746 & $3.999^{* * *}$ & 0.991 \\
Mpumalanga & 0.762 & $2.800^{* *}$ & 0.976 \\
North West & 1.175 & $3.244^{* *}$ & 1.362 \\
Northern Cape & 1.288 & $3.381^{* * *}$ & $1.580^{*}$ \\
Western Cape & 1.528 & $3.399^{* * *}$ & $1.676^{*}$ \\
\hline
\end{tabular}

Note: ${ }^{*},{ }^{* *}$ and ${ }^{* * *}$ denote significance at the $10 \%, 5 \%$ and $1 \%$ levels, respectively. The critical values are from Homm and Breitung (2012). 
Table 3. First Generation Panel Unit Root Tests

\begin{tabular}{|c|c|c|c|c|c|}
\hline \multirow{3}{*}{ Levin, Lin and Chu (2002) } & $t_{\rho}^{*}$ & $\hat{\rho}$ & $t_{\rho}^{* B}$ & $t_{\rho}^{* C}$ & \\
\hline & $-3.307 * * *$ & $-0.104 * * *$ & $-3.874 * * *$ & $-3.935 * * *$ & \\
\hline & $(0.000)$ & $(0.000)$ & $(0.000)$ & $(0.000)$ & \\
\hline \multirow{3}{*}{ Im, Pesaran and Shin (2003) } & $t_{-} b a r_{N T}$ & $W_{t, b a r}$ & $Z_{t, b a r}$ & $t_{-} b a r_{N T}^{D F}$ & $Z_{t, \text { bar }}^{D F}$ \\
\hline & -1.423 & 0.247 & 0.283 & -0.813 & 2.187 \\
\hline & & $(0.598)$ & $(0.611)$ & & $(0.986)$ \\
\hline \multirow{3}{*}{ Maddala and Wu (1999) } & $P_{M W}$ & $Z_{M W}$ & & & \\
\hline & 13.072 & -0.821 & & & \\
\hline & $(0.787)$ & $(0.794)$ & & & \\
\hline
\end{tabular}

Notes: $* * *$ indicate significance at the $1 \%$ level.

Table 4. Second Generation Panel Unit Root Tests

\begin{tabular}{|c|c|c|c|c|c|}
\hline \multirow{3}{*}{ Bai and Ng (2004) } & $\hat{r}$ & $Z_{\hat{e}}^{c}$ & $P_{\hat{e}}^{c}$ & $M Q_{c}$ & $M Q_{f}$ \\
\hline & 3 & $1.357^{*}$ & $26.140^{*}$ & 3 & 3 \\
\hline & & $(0.087)$ & $(0.097)$ & & \\
\hline \multirow{3}{*}{ Moon and Perron (2004) } & $t_{a}^{*}$ & $t_{b}^{*}$ & $\hat{\rho}_{\text {pool }}^{*}$ & $t_{a}^{* B}$ & $t_{b}^{* B}$ \\
\hline & $-4.495 * * *$ & $-3.030 * * *$ & 0.818 & $-4.168 * * *$ & $-2.944 * * *$ \\
\hline & $(0.000)$ & $(0.001)$ & & $(0.000)$ & $(0.002)$ \\
\hline \multirow{3}{*}{ Choi (2002) } & $P_{m}$ & $Z$ & $L^{*}$ & & \\
\hline & 0.498 & -1.125 & -1.024 & & \\
\hline & $(0.309)$ & $(0.130)$ & $(0.153)$ & & \\
\hline \multirow{3}{*}{ Pesaran (2007) } & $P^{*}$ & CIPS & CIPS $^{*}$ & & \\
\hline & 1 & -1.812 & -1.812 & & \\
\hline & & $(0.415)$ & $(0.415)$ & & \\
\hline
\end{tabular}

Notes: $*$ and $* * *$ indicate significance at the $10 \%$ and $1 \%$ levels, respectively. 
Table 5. Panel KSS Unit Root Test with Trend and without a Fourier Function

\begin{tabular}{cccc}
\hline Sequence & OU statistic & Min. KSS statistic & Series \\
\hline 1 & $-2.2745(0.0692)$ & -2.8308 & Limpopo \\
2 & $-2.2452(0.0704)$ & -2.7613 & Northern Cape \\
3 & $-2.3193(0.1796)$ & -2.7483 & Mpumalanga \\
4 & $-2.2478(0.1358)$ & -2.6496 & KwaZulu-Natal \\
5 & $-2.1674(0.2090)$ & -2.5770 & Free State \\
6 & $-2.0650(0.1674)$ & -2.1942 & North West \\
7 & $-2.0219(0.1080)$ & -3.1202 & Western Cape \\
8 & $-1.9728(0.2304)$ & -2.0063 & Gauteng \\
9 & $-1.9393(0.2066)$ & -1.9393 & Eastern Cape \\
\hline
\end{tabular}

Note: The maximum lag is set to be 3 . The bootstrap replications are 5000. The numbers in parentheses denote the p-value. OU statistic is the invariant average KSS statistic (Ucar and Omay, 2009). 
Table 6. Panel KSS Unit Root Test with Fourier Function and Trend

\begin{tabular}{ccccc}
\hline Sequence & OU statistic & Min. KSS & Fourier $(k)$ & Series \\
\hline 1 & $-4.7591(0.0168)$ & -2.8119 & 3 & Northern Cape \\
2 & $-4.5962(0.0280)$ & -2.8308 & 3 & Limpopo \\
3 & $-4.6836(0.0288)$ & -2.7483 & 3 & Mpumalanga \\
4 & $-4.7884(0.0378)$ & -2.5770 & 3 & Free State \\
5 & $-4.4108(0.0974)$ & -2.3934 & 3 & KwaZulu-Natal \\
6 & $-4.3275(0.0986)$ & -2.2454 & 3 & North West \\
7 & $-4.7048(0.0748)$ & -2.2223 & 3 & Gauteng \\
8 & $-4.4457(0.0460)$ & -1.9393 & 3 & Eastern Cape \\
9 & $-3.9013(0.0824)$ & -1.9063 & 3 & Western Cape
\end{tabular}

Note: The numbers in parentheses denote the p-value. The bootstrap replications are 10,000. OU statistic is the invariant average KSS statistic (Ucar and Omay, 2009). 


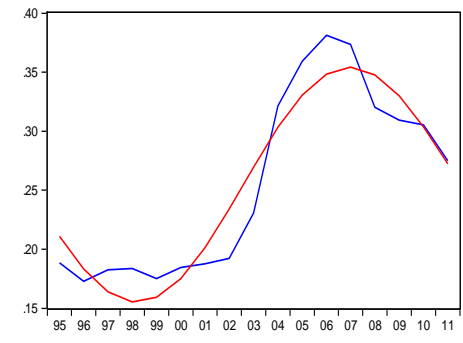

eastern_cape

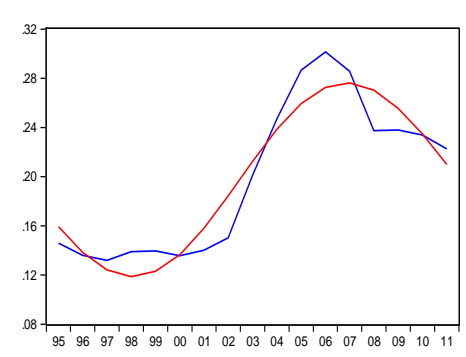

kw azulu_natal

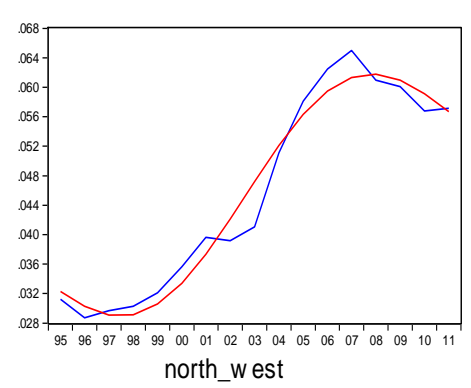

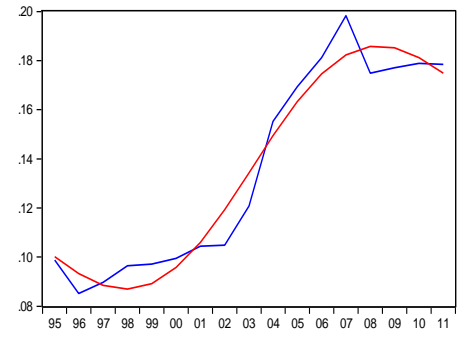

free_state

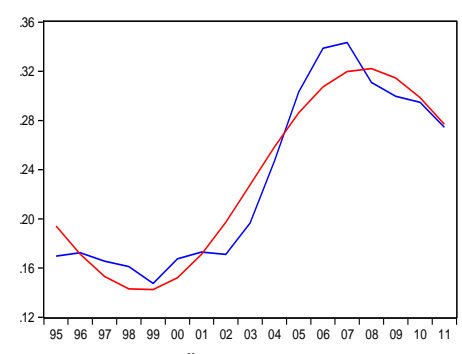

limpopo

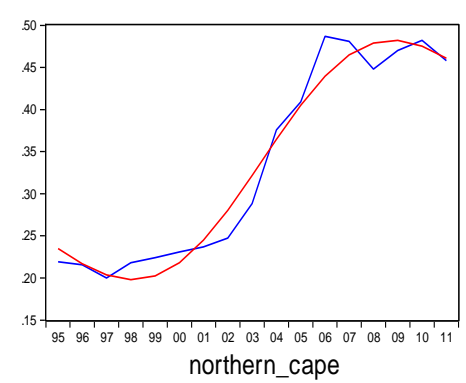

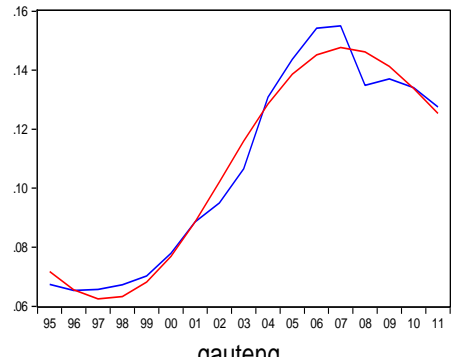

gauteng

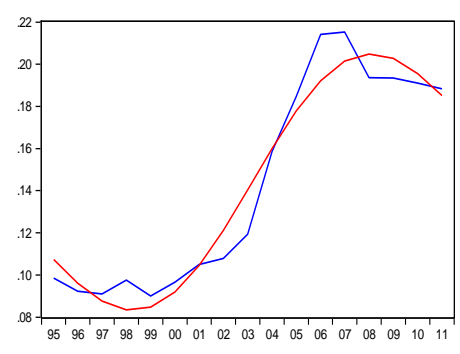

mpumalanga

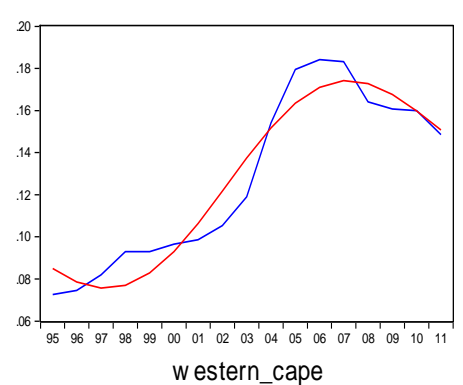

- Ratio of House Price to Income - Fitted Fourier Function

Figure 1: Time series plots of ratio of house price to income and fitted Fourier function fitted (1995 to 2011). 